\title{
El KPD en la Guerra Civil española y la cuestión del Frente Popular: algunas reflexiones*
}

\author{
Alejandro Andreassi Cieri \\ Universitat Autònoma de Barcelona
}

RESUMEN: Este artículo pretende demostrar la importancia que tuvo la participación del Partido Comunista Alemán (KPD) en la guerra civil española en la redefinición de su línea política y en el diseño de una estrategia de construcción de un frente popular tanto en el exilio como en el interior de Alemania para combatir a la dictadura nacionalsocialista. Se ha utilizado documentación perteneciente al Bundesarchiv de Berlín y a los Archives Nationales / LE CARAN (Paris). Se han analizado los debates en el seno de las Brigadas Internacionales y del exilio entre militantes comunistas y socialistas alemanes. Se han examinado algunas características de los comunistas alemanes miembros de las Brigadas Internacionales para elaborar un perfil que ayudara a comprender ese comportamiento de los miembros del KPD en España. Se concluye que la activa participación de los comunistas alemanes en la guerra civil les permitió, en contraste con la enormes dificultades para la resistencia en el interior de Alemania, tener un papel protagónico en el impulso de la línea frente populista en su lucha contra el fascismo, recuperando con ello la confianza y autoestima de estos militantes, al redimir parte de la responsabilidad del KPD en no haber sabido impedir junto al SPD la llegada del nacionalsocialismo al poder.

\section{Palabras clave: Partido Comunista Alemán (KPD); Guerra Civil; Bri- gadas Internacionales; Frente Popular; Exilio alemán.}

* Abreviaturas: SAPMO-BArch: Stiftung Archiv der Parteien und Massenorganisationen der DDR-Bundesarchiv (Berlin). AN: Archives Nationales / LE CARAN - Centre d'accueil et de recherche des Archives Nationales (Paris). Este trabajo forma parte del proyecto de investigación HAR2011-25749/HIST Las alternativas a la quiebra liberal en Europa: socialismo, democracia, fascismo y populismo (1914-1991). Agradezco las valiosas aportaciones y comentarios de los profesores Francisco Morente Valero y José Luis Martín Ramos, durante la redacción de este artículo. 
The KPD in the Spanish Civil War and the building of a Popular Front: some reflections

ABSTRACT: The aim of this article is to demonstrate the importance for the Communist German Party (KPD) of its participation in the Spanish Civil War, the redefinition of its political line, and the elaboration of a strategy to build in his exile a Front Popular against the Nazi dictatorship, especially in Germany. I have used the documentation from Bundesarchiv (Berlin) and Archives Nationales / LE CARAN (Paris). I have analyzed the debates of the exiled International Brigades between German communists and socialists. Besides, I studied some characteristics of the German communists, members of the International Brigades to draw a profile helpful to understand the behaviour of the KPD's members in Spain. I conclude that the active participation of the German Communists in the civil war allowed, in contrast to the enormous difficulties in the resistance inside Germany, to have a leading role in promoting the front populist line in its fight against fascism, thereby recovering the confidence and self esteem of these militants, to redeem part of the responsibility of the KPD in the inability to stop, with the SPD, the arrival to power of National Socialism.

KEY WORDS: German Communist Party (KPD); Spanish Civil War; International Brigades; Popular Front; German Exile.

«Desde la constitución de las Brigadas internacionales socialdemócratas y comunistas luchamos juntos contra el Fascismo. Con las armas en la mano hemos logrado la unidad en las trincheras de España» ${ }^{1}$

Los historiadores que han estudiado la trayectoria del partido comunista alemán (KPD) desde su fundación hasta 1945 llegan a la conclusión de que éste habría perdido toda autonomía política y se habría transformado en un relativamente dócil peón del PCUS y de la dictadura estalinista ya durante la República de Weimar, y con seguridad a partir del comienzo de la dictadura nazi, lo que explicaría incluso su comportamiento en la segunda posguerra. Ese proceso de subordinación del comunismo alemán, denominado como su «estalinización», estaría caracterizado por la liquidación de la democracia interna partidaria y su sustitución por una organización fuertemente disciplinada bajo el comando de un poder centralizado que le otorgaría un carácter

1 SAPMO-BArch, SgY 11/ V 237/ 1 /13, p. 45, 7/1/1938: "Seit Bestehen der Internationalen Brigaden kämpfen wir Sozialdemokraten und Kommunisten gemeinsam gegen den Faschismus. Mit der Waffe in der Hand haben wir in den Schutzengräben in Spanien die Einheit verwirklicht“. 
monolítico y jerárquico, la completa subordinación a la política exterior de la URSS - a la que debería ajustar toda su acción política- y la dependencia financiera del KPD del Comintern ${ }^{2}$. Sin embargo, no todos los autores están de acuerdo con ese enfoque y lo han rebatido, al menos de forma parcial, introduciendo matices que recuperan el peso de la influencia de las circunstancias locales en las que le tocó actuar al KPD, y que interactuaron con la indudable influencia que ejerció sobre el comunismo alemán tanto el Comintern como también el comunismo soviético. El predominio de unas u otras influencias permite además identificar diferencias diacrónicas en el curso de la evolución del KPD durante la República de Weimar así como a partir de $1933^{3}$. Klaus-Michael Mallmann, por ejemplo, otorga una gran importancia a los denominados «milieus», medio-ambientes donde predominaban culturas políticas que permitían la convivencia, a nivel local, entre socialdemócratas y comunistas. Afirma que en ellos habían persistido las tradiciones de cultura obrera y popular surgidas del seno de la sociedad en paralelo, cerrada y antagónica con la de la burguesía que había elaborado de forma sostenida el movimiento obrero alemán durante el Kaiserreich bismarckiano y guillermino. ${ }^{4}$ Mallmann demuestra que, no sólo antes de 1923, sino incluso en 1929 y en 1932, se reproducían en numerosos centros de trabajo y localidades de Alemania la convergencia y colaboración recíproca entre comunistas y socialistas, a pesar de las consignas antagónicas de las direcciones de ambos partidos, así como de la presencia de un conflicto inmanente entre vanguardia y base militante de algún modo constitutivo del KPD y diferente a la coexistencia plural de corrientes. Como ejemplo, cita esta declaración de un miembro del KPD en la Cuenca del Ruhr:

Con el Reichbanner del SPD hemos realizados acciones conjuntas. No estamos enfrentados, sólo en las elecciones. Además todos nos conocemos. Pero cuando aparecen los nazis, los enfrentamos conjuntamente. No son socialfascistas como afirma la línea oficial. Todos los socialdemócratas son trabajadores. Frecuentemente nos encontramos con ellos para discutir. Cuando en 1932 se produjo el golpe de estado (putsch) contra Braun-Severing, estuvimos reunidos esperando la señal para lanzarnos a la lucha5 .

2 WEBER, 1969. Inicialmente este autor databa el comienzo de ese proceso a partir de 1924, pero en una obra reciente lo adelanta, al período de 1921-22 lo que le obliga a considerar el proceso como una bolchevización más estalinización, ver LAPORTE, 2008: 23-25.

3 MALLMANN, 1996. WEITZ, 1997.

4 MALLMANN, 3 (Berlín, 1999): 403-406. Este autor denomina a esa sociedad en paralelo "nicho ecosocial socialista del Kaiserreich [sozialistischen Nischengesellschaft des Kaiserreiches]",

5 MALLMANN, 3 (Berlín, 1999): 409. 
Los planteamientos de Mallmann coinciden en gran parte con los enunciados hace más de treinta años por Milos Hájek en su libro, ya clásico, sobre el Comintern, así como con los de otros autores, como Donna Harsch, quien ha estudiado las relaciones entre socialdemócratas y comunistas frente al avance del nazismo, desde la perspectiva del $\mathrm{SPD}^{6}$. Si bien estos planeamientos se centran más en el período previo a 1933, podemos hallar otros, como el de Detlev Peukert o el de Miloš Hájek, que sostienen que el giro hacia la recuperación de la propuesta del Frente Único, núcleo esencial de cualquier ampliación de la alianza antifascista hacia otros sectores políticos y sociales, se detecta en las iniciativas locales de organizaciones comunistas para llegar a acuerdos con las organizaciones socialdemócratas con el fin de enfrentar a la dictadura nazi, que se anticipaban a las decisiones tanto del vértice del KPD como del Comité Ejecutivo del Comintern? ${ }^{7}$. Los motivos de estas decisiones caben ser atribuidos a percepciones de las dificultades de la lucha antifascista a nivel local, ya que a nivel de la dirección del KPD predominaba el rechazo al Frente Único y, en general e inclusive en los medios de la IC, continuaba vigente la línea del «Tercer período» y se continuaba utilizando el término «social-fascismo» para referirse al $\mathrm{SPD}^{8}$.

También citan estos autores cuestiones de orden general que contribuían a recuperar la propuesta del frente único. Entre ellas incluyen el impacto del 30 de junio de 1934 - que, con el fortalecimiento definitivo del régimen hitleriano, disipaba las expectativas de una crisis próxima que favorecería su derrocamiento-, la insatisfacción popular por las situación socioeconómica y su disposición a la movilización masiva contra el régimen, las enormes dificultades para el trabajo político clandestino y el mantenimiento en pie de las organizaciones brutalmente golpeadas por la acción de la Gestapo. A todo ello suman el proceso desarrollado en Leipzig contra los acusados del incendio del Reichstag, que fue acompañado de una intensa campaña internacional en su defensa en la que participaron comunistas, socialistas y demócratas9. Pero también existían factores que persistían en dificultarla, ya que no se habían disipado los recelos recíprocos de comunistas y socialdemócratas, empeñados todavía en acusarse mutuamente como responsables de la llegada de los nazis al poder. La consecuencia, entre otras, era el mantenimiento por una

6 HÁJEK, 1984. HARSCH, 1993: 196-202.

7 Iniciativas similares, que anticipan la línea que se aprobará en el VII Congreso pero que niegan la «línea oficial» del Tercer Período, pueden apreciarse también en partidos comunistas de la importancia del PCF, como muestra la intervención de Maurice Thorez en el congreso del Partido Radical en el otoño de 1934 proponiendo por primera vez el «frente nacional», sin que ello correspondiera - parece que más bien al contrario- a una instrucción previa de Togliatti, del Comintern; ver : AGOSTI, 2003: 176-178. BROUÉ, 1997: pág. 658.

8 HÁJEK, 1984: 297-299. PEUKERT, 1980: 222-229.

9 PEUKERT, 1980: 220-221. HÁJEK, 1984: 265. 
parte del KPD de su línea ultraizquierdista y sectaria, en la vana expectativa de que, aunque menguados por la represión, constituían la única organización alrededor de la cual podría estructurarse la resistencia y el eventual derrocamiento de la dictadura hitleriana ${ }^{10}$.

Por lo tanto, es mi intención observar si esa relativa autonomía de los comunistas alemanes durante la República de Weimar, que había permitido acuerdos coyunturales con los socialdemócratas y otras organizaciones del movimiento obrero, reaparece en la actividad de los militantes del KPD que participaron en la guerra civil española. También en este caso en relación con el desarrollo y materialización de las políticas de frente único y frente popular, que continuaban siendo motivo de desacuerdos y falta de concreción entre la dirección del KPD y sus bases, y entre aquella y la dirección socialdemócrata, a pesar de su sanción en el VII Congreso del Comintern ${ }^{11}$. Debemos tener en cuenta que contribuía a esas dificultades la paranoia oficial procedente de Moscú y transmitida por la dirección del KPD sobre las «infiltraciones» de trotskistas y otros agentes antisoviéticos en las filas de las organizaciones que oficialmente participaban en los preparativos del Deutsche Volksfront en París. Las denuncias sobre estos conflictos realizadas desde el aparato del KPD en pleno 1937, en las que se acusaba de acción disolvente dentro del partido a miembros de la Facción Conciliadora o a partidarios de Brandler y Thalheimer, sugieren que, junto a la habitual retórica que procuraba criminalizar a la disidencia en el partido, existían grupos de militantes del KPD que estaban actuando y sosteniendo posiciones heterodoxas respecto a la dirección y a las posiciones más próximas al PCUS ${ }^{12}$.

En consecuencia, planteo como hipótesis que fue su aislamiento como organización política, su conversión en un «partido de exiliados», lo que condujo a los miembros del KPD que habían acudido en ayuda de la Segunda Re-

10 HÁJEK, 1984: 297-298. Para este autor, uno de los datos que confirman esa situación era el relativamente significativo trasiego de militantes socialdemócratas a las filas del KPD.

11 El SPD rechazó las primeras ofertas del KPD sobre un frente común antinazi aduciendo que «todavía estaban frescas en la memoria las maniobras y mentiras del KPD sobre la unidad de acción de 1922 y 1923», Wolfgang Benz, 2004: p. 194. La reticencia y las dudas de la socialdemocracia sobre la conveniencia del acuerdo con los comunistas no sólo se registra en el caso alemán; también aparecen en donde había circunstancias más favorables, como era el caso de Francia: mientras el PCF había conseguido imponer la propuesta del frente popular por el presidium del ejecutivo del Comintern a finales de 1934, la SFIO recién la aprobaría en junio de 1935 en el congreso de Mulhouse, HÁJEK, 1984: 302-304.

12 Un informe confidencial del KPD afirmaba a fines de julio de 1937, en medio de la ola represiva de los procesos de Moscú desatada por el régimen estalinista, que: «... con la ayuda de grupúsculos, ante todo sus agentes en el SAP [que participaba en el Deutsche Volksfront] dirigen los trostkistas su trabajo de desmoralización en las filas de los antifascistas alemanes alcanzando hasta al mismo SPD», también denunciaba la acción de grupos «brandleristas», F/7/15131/8/a, AN (Paris). 
pública, al menos a quienes estaban directamente implicados en la contienda, a considerar su concreta intervención en la lucha antifascista como el nuevo «nicho social» [Nischengesellschaft, según Mallmann]. Éste sería más limitado pero también eficaz, y le permitiría la recuperación del activo político del comunismo alemán y por lo tanto de su autonomía y capacidad de iniciativa, anuladas en el interior por la brutal represión a manos de la Gestapo y, en el exterior, por la fragilidad de su existencia como exiliados, que habían acentuado su dependencia de la URSS y de la dirección de la IC ${ }^{13}$. España, siguiendo la idea de Mallmann, habría sido el segundo «milieu» para los comunistas alemanes, reactivando una cultura política sepultada por la práctica sectaria y absurda del «Tercer período». Los ámbitos en que se manifestaría esa recuperación serían las iniciativas alrededor de la política de alianzas con otros sectores antifascistas.

Entre 1935 y 1936 se puede localizar un punto de inflexión tanto en el funcionamiento como en la estrategia política que debía seguir el KPD. Dicho punto viene determinado por tres circunstancias. La primera es la necesidad de situar a la dirección del partido fuera de Alemania, colocando a los diversos responsables en países limítrofes, luego de la caída de las direcciones interiores - la de Berlín en marzo y las de los distritos del oeste entre mayo y junio de 1935. La segunda es la definitiva adopción por el KPD de la línea aprobada en el VII Congreso de la IC: la construcción de los frentes populares, en la llamada Conferencia de Bruselas ${ }^{14}$, en la que también se erigen como líderes del partido Wilhelm Pieck y Walter Ulbricht sustituyendo a los seguidores de Ernst Thälmann ${ }^{15}$. La tercera es la decidida implicación de los militantes del KPD en la guerra civil española en defensa de la república es-

13 WEITZ, 1997: 280-281 y 286-291.

14 Esta conferencia se había celebrado en Moscú, pero se la situó en Bruselas por razones de seguridad, ver MERSON, 1985: 163.

15 Esta sustitución era el resultado de la reconsideración y crítica de la errónea línea «ultraizquierdista» seguida a partir del VI Congreso del Comintern, celebrado en 1928, que fue sustituida por la progresiva aceptación de una política de alianzas cuyo eje principal debía ser la acción conjunta con el SPD para enfrentar al nazismo. Debemos tener en cuenta que esa sustitución de línea política y de dirigentes no careció de apoyo en las estructuras y la base del KPD desde el momento en que varias organizaciones del mismo mantuvieron relaciones con grupos socialdemócratas, especialmente en el norte y oeste de Alemania, lo que constituye otra expresión de la persistencia de una continua lucha ideológica y programática en el seno del KPD, que reconoce antecedentes en la trayectoria del partido durante la República de Weimar. Con ella se restituía en parte la línea política sostenida hasta 1923, y abandonada luego del fracasado levantamiento de octubre de ese año, aunque no llegó a significar la rehabilitación de Brandler y Thalheimer -quienes dirigían el KPD en aquel momento- por la nueva dirigencia encabezada por Pieck y Ulbricht. Debe tenerse en cuenta que éste último se había alineado con Thälmann en los conflictos internos previos al VI Congreso. HÁJEK, 1984: 81-95 y 297-299. KINNER, 2005, vol. 1: 57-78. 
pañola. Las tres circunstancias produjeron en los militantes del partido, tanto en los que continuaban la lucha en la clandestinidad en el interior como en quienes participaban en el exilio, la sensación de apertura de una nueva etapa, un nuevo comienzo y, tal vez, una segunda oportunidad para el comunismo alemán. También estas circunstancias indujeron un cambio de actitudes y expectativas en los miembros del partido. Paradójicamente, como explica Detlev Peukert, las exigencias de férrea disciplina que conllevaba la lucha clandestina se vieron moduladas por las de los militantes del interior, quienes muchas veces rechazaban determinadas directrices procedentes de los cuadros en el exilio. Así mismo, también entre los exiliados aparecieron exigencias de una mayor democracia interna, la libre elección de los dirigentes y la cogestión del partido, tal como plantearon los miembros del KPD en Holanda en 193816. A pesar del redoblado intento de mantener los marcos de discusión bajo control, era inevitable la aparición de opiniones divergentes e incluso contradictorias con la línea oficial. Es dable suponer que a este estado de debate interno, con mayor o menor intensidad según las circunstancias y oportunidades, no fueran ajenos los militantes comunistas que estaban participando en la guerra civil española y especialmente los que estaban encuadrados en las Brigadas Internacionales.

También podemos agregar otros factores favorables a la renovación de la capacidad de intervención política del KPD: la recuperación de la autoestima colectiva como miembros de una organización política a la que se le presentaba la oportunidad de enfrentar al fascismo y contribuir a vencerlo, la participación en el soporte práctico y no sólo político-ideológico de una experiencia de frente popular como la que se estaba produciendo en España y la posibilidad concreta de colaboración mutua con los socialistas alemanes, especialmente en el ámbito de las Brigadas Internacionales. Por último, debe considerarse como factor decisivo en la importancia que adquirió la actividad del KPD en relación a España el descenso de la actividad resistente en Alemania por efecto de la implacable represión ejercida por la Gestapo. A partir de 1936 se detectan indicios de una marcada disminución de la actividad clandestina en relación al período 1933-1935, trasladándose el peso mayor de la actividad al exilio ${ }^{17}$.

\section{LA PARTICIPACIÓN DEL KPD EN LAS BRIGADAS INTERNACIONALES}

Oficialmente la constitución de las Brigadas Internacionales data del 22 de octubre de 1936, cuando lo autoriza expresamente el gobierno de la Repúbli-

16 PEUKERT, 1980: 252-257.

17 PEUKERT, 1980: 261-263. 
ca, aunque se constata la participación de militantes comunistas alemanes en los combates en Barcelona contra los militares sublevados a partir del 19 de julio. La información sobre la llegada de estos militantes a Barcelona sugiere que, al principio, se trataba más de una decisión personal o de pequeños grupos que de la consecuencia de un envío de voluntarios planificado y organizado por parte del KPD. Varios de ellos se encontraban en Barcelona desde días antes del golpe militar, con motivo de su asistencia a la Olimpiada Popular convocada como acto de rechazo a las olimpíadas que se estaban realizando en Berlín, mientras que el llamamiento del Comité Central del KPD a la defensa de la legalidad republicana no se produjo hasta el 7 de agosto de $1936^{18}$. El 22 de julio, luego de la ocupación del Hotel Colón, constituirán el «Grupo Thälmann» y a partir del 24 de julio se dirigirán hacia Aragón para combatir a los sublevados, integrados en la columna «Trueba-Del Barrio» de la UGT, que luego será rebautizada como «Carlos Marx» ${ }^{19}$. Desde los momentos iniciales de la devenida guerra civil, existía una estricta delimitación de las unidades según afiliaciones e ideologías; sin embargo, ello no impidió que los voluntarios alemanes compartieran experiencias de lucha junto a anarquistas, a tal punto que algunos de sus miembros proponían que la columna se denominara «Bakunin-Marx». Se produjeron reacciones opuestas; por una parte, los recelos frente a las intenciones reales o imaginarias de captación de militantes por las otras organizaciones antifascistas; por otra, un contexto que favorecía la unidad y la colaboración activa en la lucha entre las fuerzas antifascistas. Ejemplos de lo primero son, por ejemplo, las trayectorias de Egon Illfeldt y Emil Hessenthaler, pertenecientes al KPD, que del «Grupo Thälmann» pasaron al DAS (Deutsche Anarchosyndicalisten), para colaborar más tarde, respectivamente, con el Comité Regional de la CNT y con la FAI en Madrid hasta $1937^{20}$. Representativo de lo segundo es la importancia que otorgaban los voluntarios comunistas alemanes a la constitución del PSUC, cuya fundación saludaban no sólo como un gesto de cortesía a los

18 KINNER, 2005, VOL. 2: 207. SKOUTELSKY, 2006: 37-45. CASTELLS, 1974: 19-35.

19 Informe de Werner Hermelin, perteneciente al servicio de prensa en Albacete y previamente comisario político para todos los combatientes extranjeros en el frente de Aragón, quien además señala que el KPD estaba en estado de alerta tres días antes del inicio de la sublevación militar, SAPMO-BArch, SgY 11/V 237/ 1/4, pp. 1 y 53.

20 Egon Illfeld perteneció al KPD, como miembro de este partido fue condenado a seis meses de prisión, marchando luego al exilio, primero en el Sarre y más tarde en España, donde se incorporó al «Grupo Thälmann», del que formó parte hasta septiembre de 1936 combatiendo en el frente de Aragón, adhiriendo luego la DAS y colaborando con el Comité Regional de la CNT hasta el fin de la guerra; Emil Hessenthaler, también miembro del KPD, después de pasar por el «Grupo Thälmann» se unió al DAS y hasta mayo de 1937 colaboró con la FAI, ver NELLES, LINSE, PIOTROWSKI, GARCÍA, 2010: 414-415. También “'Grupo Thällmann' Die Ereignisse der ersten Woche nach dem 19. Juli”, SAPMO-BArch, SgY 11/ V 237/1/4, 1. 
camaradas catalanes que les acogían en sus filas, sino que en la nueva formación veían la proyección y la objetivación de sus aspiraciones respecto a la recuperación del Frente Único, como prerrequisito para un frente alemán antifascista. Debe agregarse la experiencia del propio grupo Thälmann, que compartía sus primeras acciones de combate con militantes de otras tendencias, en un clima de cierta coexistencia ideológica. En el mismo informe en que destacaban la formación del PSUC, anunciaban su incorporación al mismo reconociendo que lo hacían «...a pesar de que, obviamente, había también muchos anarquistas y republicanos entre nosotros», lo cual era un reconocimiento tácito de que, al menos en ese momento, la diversidad ideológica no era obstáculo si existía una firme decisión de unidad antifascista ${ }^{21}$.

A partir de este núcleo inicial se irían conformando en poco tiempo los dispositivos más importantes de las Brigadas Internacionales. Después del grupo Thälmann se organizarán, ya bajo la supervisión del KPD y el Comintern, los tres batallones alemanes, integrados en la brigada XI, que llevarán el nombre, respectivamente, de Edgar André, Ernst Thälmann y Hans Beimler, luego de la muerte de éste en el frente de Madrid. Los miembros del KPD serán los más numerosos entre los brigadistas de habla alemana. De un total de 4.221 brigadistas, a finales de 1937, el 70,8 por ciento correspondía a militantes comunistas y sólo el 8,7 por ciento a militantes socialistas o pertenecientes a otras organizaciones antifascistas, mientras que el resto eran independientes o no se conoce su filiación política ${ }^{22}$. Al mismo tiempo se organizará una efectiva propaganda a favor de la República española y del reclutamiento de voluntarios para las Brigadas Internacionales (BI), especialmente en Francia, donde se concentraba una gran mayoría de exiliados. En esta tarea tendrá una actividad central Willi Münzenberg, dirigente principal de IAH (Ayuda Obrera Internacional) ${ }^{23}$ y miembro del KPD, quien a fines de julio de 1936 creó el Comité de Ayuda a la República Española ${ }^{24}$.

La experiencia de colaboración de los brigadistas con el pueblo español no se limitaba a los combates sino que abarcaba también las actividades de carácter civil que desarrollaban en los diferentes pueblos en que se hallaban ${ }^{25}$.

21 “Die Thälmann Gruppe - die erste internationale Einheit", SAPMO-BArch, SgY 11/ V 237/1/4, 65 .

22 SAPMO, ZPA, V 237/4/24: 96.

23 Willy Münzenberg había sido el fundador de este organismo internacionalista creado por una iniciativa de Lenin en agosto de 1921, ver: ANDREASSI, 2010: 40; GROSS, 2007: 389-390.

24 NIEMEYER, 2001: 162.

25 Para una información detallada sobre el funcionamiento y organización de las Brigadas Internacionales y especialmente de su base en Albacete, así como sobre las relaciones mantenidas con el tejido social y político local, consultar REQUENA GALLEGO, 1998: 147179. También ver SKOUTELSKY, 2006: 71-87. 
Constituyendo comisiones políticas que reunían a los representantes del Frente Popular local, del Socorro Rojo Internacional (SRI) y a miembros de las BI, organizaban y desarrollaban tareas vinculadas a la salud pública, a la educación y la cultura, intentando conseguir la complicidad del campesinado, «de cuya ayuda, para que en el frente no faltara nada de lo necesario, dependía la futura victoria», y proyectaban esa actividad como un motivo y resultado de la colaboración entre comunistas y socialistas, por lo tanto como una objetivación del Frente Único ${ }^{26}$. Esta es una actividad que las BI continuaron incluso después de su despedida oficial por el gobierno republicano, en diciembre de 1938; un buen ejemplo de ello fueron las actividades de los hogares infantiles para niños refugiados y residentes en las localidades de Montesquiu y Bisaura de Ter (Sant Quirze de Besora) de Cataluña ${ }^{27}$. Esta última actividad se desplegaba en el marco de una apreciación optimista de la situación en Alemania, que los hechos demostrarían errónea, que auguraba la profundización de las dificultades para el régimen nazi y las crecientes perspectivas para la consolidación de un frente popular en el interior, capaz de derribar a la dictadura cuando se hiciera insoportable la tensión entre las exigencias económicas de la carrera armamentista — que estaban llegando a su clímax a comienzos de 1939 - y las necesidades populares ${ }^{28}$.

Otro de los aspectos fue el de la formación de los militantes para que colaboraran con el PCE. A fines de 1937 comenzó a funcionar la escuela de cuadros del KPD en Pozo Rubio, Albacete, que tenía por objetivo la adaptación de sus miembros en España a las necesidades y tareas de PCE, pero que también se consideraba como una contribución a la lucha contra el régimen hitleriano, como parte de la lucha en el interior de Alemania. El programa de actividades definía claramente los temas alrededor de la conquista de la unidad de acción, el frente único y el objetivo de la constitución del partido obrero unificado, para lo cual el PSUC constituía un referente, hasta el punto que, en la bibliografía indicada a los partícipes en la escuela, junto a Marx, Engels Lenin y Stalin se incluían textos de Joan Comorera ${ }^{29}$. Su director sería Anton Ackermann, autor de un texto en el que elabora el concepto de «democracia popular», que constituiría la definición oficial del KPD, redactado en mayo de 1937 en Barcelona ${ }^{30}$.

26 "Versammlung abgehalten an 18 um 8 Uhr nachts von der politischen Kommission", SAPMO-BArch, SgY 11/ II 237/ 1 /8, p. 30, 5/6/1937. Incluso de la XI Brigada dependía un hogar infantil, SAPMO-BArch, SgY 11/ II 237/ 1/8, pp. 62-63.

27 "Arbeitsplan des Kinderhilfskomitee der Brigade und der Ortskomitees in Bisaura de Ter und Montesquiu", SAPMO-BArch, SgY 11/ II 237/ 1/8, pp. 85-86.

28 “DEUTSCHLAND NEUJAHR 1938-39”, SAPMO-BArch, SgY 11/ II 237/ 1 /8, pp. 80-82.

29 SAPMO-BArch, SgY 11/ II 237/ $1 / 7$.

30 LANGKAU-ALEX, 2004: 576. 


\section{PERFIL DE LOS MiEMbros DEL KPD EN LAS B.I.}

A continuación se esboza una aproximación al perfil de los militantes del KPD que participaron en las B.I. a partir de una muestra de 131 brigadistas pertenecientes a dicho partido ${ }^{31}$. He construido dos distribuciones de frecuencias, una sobre la estructura de edades del grupo, otra relativa a la antigüedad de pertenencia al KPD hasta su llegada a España, y una serie temporal sobre las fechas de su arribo al país; he contabilizado también el perfil profesional de los militantes.

La distribución por edades nos muestra un predominio de los mayores de 30 años (la media de edad es de 35 años, desviación estándar 6 años y un coeficiente de variación de 17,58\%) Estos últimos parámetros nos indican una relativa homogeneidad etárea, lo cual revela la escasa renovación de militantes, comprensible ante la brutal represión que sufría el KPD en Alemania.

GRÁFICO 1. EDAD DE LOS BRIGADISTAS ALEMANES AL LLEGAR A ESPAÑA

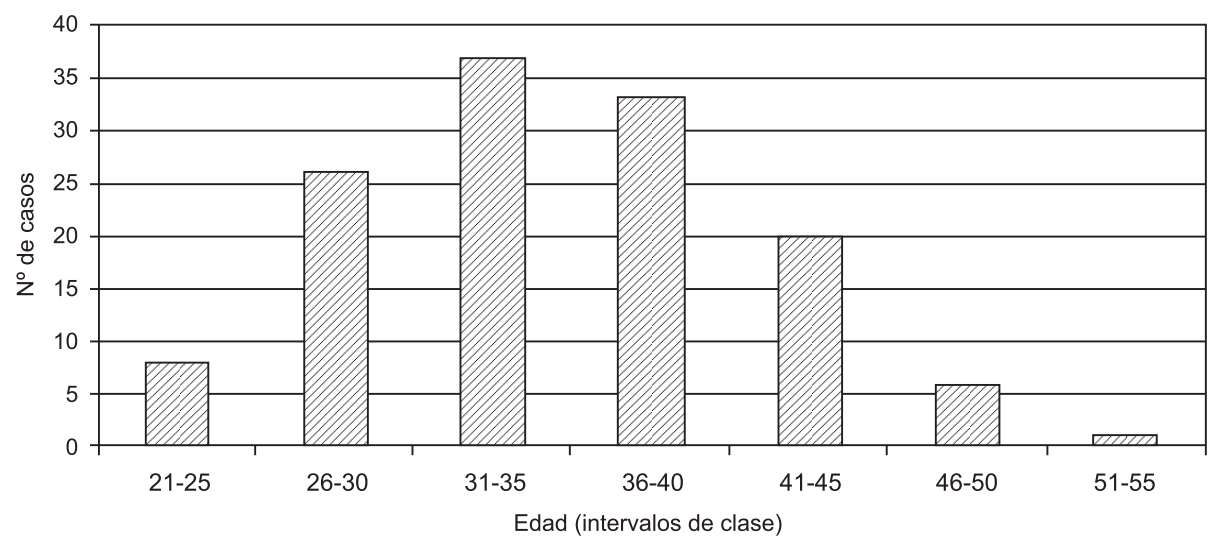

Fuente: SAPMO-Barch SgY11/V237/1/2 $\mathrm{n}=131$

31 SAPMO-BArch SgY11/V237/1/2 y /3 
TABLA 1. ESTRUCTURA SOCIAL DE LOS MIEMBROS DEL KPD, VOLUNTARIOS EN ESPAÑA

\begin{tabular}{|l|r|r|}
\hline Estructura social de los miembros del KPD, 1927 & \multicolumn{1}{|c|}{ № } & $\mathbf{\%}$ \\
\hline Trabajadores industriales cualificados & 57154 & $39,9 \%$ \\
\hline Trabajadores industriales no cualificados & 40346 & $28,2 \%$ \\
\hline Trabajadores agrícolas & 3164 & $2,2 \%$ \\
\hline Campesinos & 143 & $0,1 \%$ \\
\hline Clases medias* & 3164 & $2,2 \%$ \\
\hline Empleados & 2477 & $1,7 \%$ \\
\hline Oficiales de bajo nivel & 1088 & $0,8 \%$ \\
\hline Artesanos y comerciantes & 13702 & $9,6 \%$ \\
Funcionarios sindicales & 3737 & $2,6 \%$ \\
\hline Funcionarios de partido & 2348 & $1,6 \%$ \\
\hline Otros & 15935 & $11,1 \%$ \\
\hline ToTAL & $\mathbf{1 4 3 2 5 8}$ & $\mathbf{1 0 0 , 0 \%}$ \\
\hline
\end{tabular}

* incluye oficiales de rango medio, profesores liberales y pequeños empresarios

Fuente: Eric Weitz, Creating German Communism. 1890-1990, Princeton, 1997, p. 245

La estructura social revela el predominio absoluto de los trabajadores industriales - $\mathrm{y}$, entre éstos, el de los más cualificados - respecto a otras categorías. En ese sentido se asemeja bastante a la estructura del KPD durante la República de Weimar, aunque con un fuerte sesgo a favor especialmente de las actividades más cualificadas ${ }^{32}$.

La antigüedad en el KPD en el momento de su llegada a España es uno de los datos más interesantes en cuanto a la tipología de estos militantes. Casi el 60 por ciento tienen una antigüedad mayor de una década, lo cual indica que habían tenido la oportunidad de convivir con las distintas culturas políticas que se habían desarrollado antes del VI Congreso de la IC, el inicio del tercer período y la «táctica de clase contra clase» que tan desastrosos resultados iba a producir especialmente en Alemania. Un número no despreciable de los mismos revistaban en el KPD desde su fundación, y un 30-35 por ciento lo hacían al menos desde 192021, lo que posiblemente les permitió participar en los primeros debates sobre la oportunidad del Frente Único y su práctica, ya iniciados en la época en que Paul Levi ocupaba el secretariado, y contrastarlo con la llamada «teoría de la ofensiva», signo distintivo del ala izquierda de la IC, contemporánea de aquella, y fundamento ideológico de la fracasada insurrección de 1923.

32 Por ejemplo, esta estructura registrada en Wienand Kaasch, "Die soziale Struktur der KPD”, Die Kommunistische Internationale, 9:19 (1928) en WEITZ, 1997: 245. 
GRÁFICO 2. AÑos DE MILITANCIA DE LOS BRIGADISTAS EN EL KPD AL LLEGAR A ESPAÑA

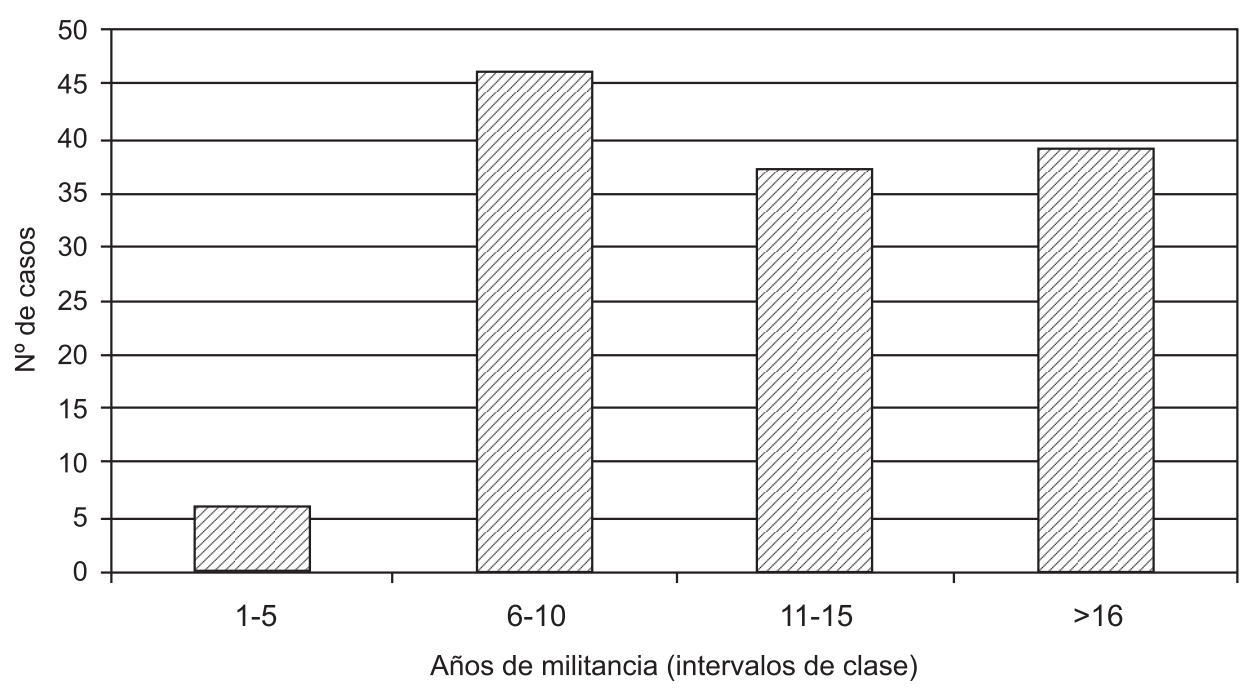

Fuente: SAPMO-Barch SgY11/V237/1/2 $\mathrm{n}=128$

GRÁFICO 3. LLEGADA A ESPAÑA DE LOS MILITANTES DEL KPD PARA SU INCORPORACIÓN A LAS BRIGADAS INTERNACIONALES

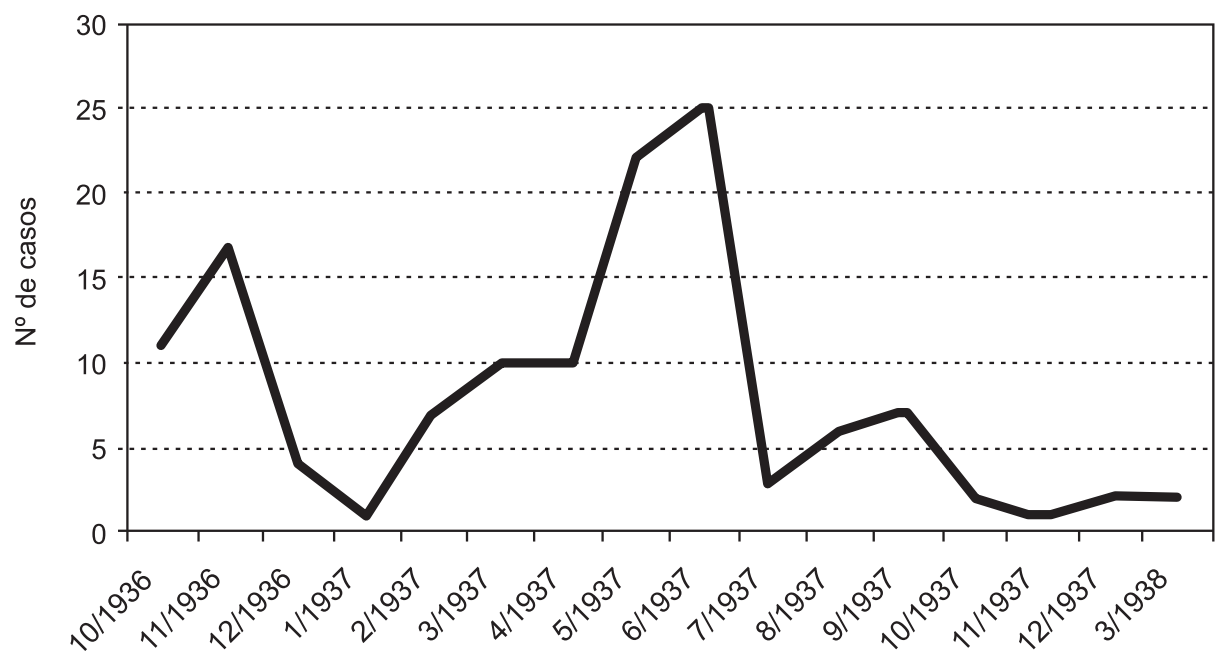

Fechas de llegada

Fuente: SAPMO-Barch SgY11/V237/1/2 $\mathrm{n}=130$ 
Los miembros del KPD correspondientes a la muestra estudiada llegaron fundamentalmente en dos oleadas. La primera, que corresponde al período formativo de las brigadas aunque ya bajo el control de sus organizaciones políticas, a diferencia de la etapa inicial, correspondiente al primer mes del conflicto. La segunda oleada coincide con la etapa álgida de los enfrentamientos en Cataluña, el fin del gobierno Largo Caballero y la fase inicial del gobierno Negrín. Según muestra el gráfico, la llegada de estos miembros del KPD se produciría mayoritariamente una vez superados los conflictos en la retaguardia republicana y estabilizada la situación política, al menos momentáneamente, con la constitución del nuevo gobierno de la república. ${ }^{33}$ La mayoría, a diferencia de los llegados en la primera oleada, ocuparían cargos de responsabilidad entre los voluntarios, especialmente como comisarios políticos.

\section{EL FRENTE POPULAR Y SUS OBJETIVOS}

A mediados de 1938, el KPD evaluaba que la situación interna de Alemania se deterioraba como consecuencia de la aplicación del Plan Cuatrienal, dirigido por Goering, que golpeaba a cada vez más amplios sectores de la población provocando una desafección creciente. A ello agregaban los acontecimientos que habían culminado el 4 de febrero de 1938 con la destitución de Von Blomberg y Fritsch de la jefatura de la Wehrmacht y la asunción por Hitler del comando directo de la misma, así como la sustitución de Konstantin von Neurath por Ribbentrop al frente del Ministerio de Asuntos Exteriores, todo lo cual era evaluado en los medios del exilio como pruebas de que la crisis del régimen nazi se estaba manifestando en la cúpula del poder ${ }^{34}$. Además era objeto de especial preocupación la cada vez más agresiva política exterior de Hitler, manifestada no sólo por la intervención abierta en la guerra civil española, sino también por la reciente anexión de Austria y las amenazas a Checoslovaquia, que aumentaban a su juicio la inminencia de una guerra europea. Por ello se suponía que estaban madurando las condiciones para el desarrollo de una resistencia a la dictadura que debía plasmarse en la constitución de un Deutsche Volksfront (Frente Popular alemán) en el interior, objetivo al que se habían dedicado los esfuerzos por consolidar el Comité para un Frente Popular alemán en el exilio. Así se manifestó el CC del KPD en su declaración del 14 de mayo de 1938, reafirmando la «necesidad de reunión de todos los antifascistas en el Frente Popular alemán [Deutsche Volksfront]»,

33 De la abundante literatura sobre los sucesos de mayo de 1937 en Barcelona, destaco tres obras recientes, los excelentes libros de: VIÑAS, 2007. MARTÍN RAMOS, 2010. GALLEGO MARGALEFF, 2007.

${ }^{34} \mathrm{~F} / 7 / 15131,8$ b. b1., AN (Paris), 17/02/1938. 
señalando que lo debían integrar la clase obrera y el campesinado, las clases medias representadas principalmente por los sectores vinculados a la intelectualidad, y el artesanado. Desde el punto de vista político, el KPD consideraba que dicho frente debía abarcar un espectro más amplio, que incluía al Zentrum y a los «otros partidos burgueses», las ligas juveniles e incluso al Casco de Acero [Stahlhelm], al tiempo que como táctica general se indicaba la necesidad de que los antifascistas actuaran en las organizaciones de masas fascistas, como el DAF, para arrebatar el control de las mismas al aparato nazi ${ }^{35}$. Al mismo tiempo afirmaba que la realización de los objetivos de la unidad antifascista no exigía el abandono de las convicciones políticas e ideológicas por parte de ningún miembro del frente popular ${ }^{36}$.

Como antecedentes de estos intentos del KPD y el SPD de llegar a acuerdos que condujeran a la constitución de un frente popular, debe apuntarse en primer término la propuesta de febrero de 1935 realizada por Wilhem Pieck y Walter Ulbricht, con el respaldo de una parte del Comintern, a la dirección del SPD, exilada en Praga, de un «Pacto para el Frente Único», reiterada sucesivamente en el VII Congreso de la IC y en la Conferencia de Bruselas de los comunistas alemanes. Sin embargo, las heridas que habían producido los conflictos entre socialdemócratas y comunistas no habían cicatrizado aún, la desconfianza de los primeros hacia los últimos todavía era vigente y, por lo tanto, la primera respuesta socialdemócrata fue la del rechazo. ${ }^{37} \mathrm{~A}$ pesar de ello, la formación de los frentes populares francés y español estimuló la constitución en febrero de 1936, en París, de un «Comité para la organización del Frente Popular alemán» [Ausschuß zur Vorbereitung einer deutschen Volksfront], presidido por Heinrich Mann, en el cual participaban por el SPD Rudolf Breitscheid y Max Braun, y por el KPD Willi Münzenberg y Herbert Wehner, y más tarde Willy Brandt por el SAP ${ }^{38}$, así como escritores como

35 La llamada táctica «del caballo de Troya», WEITZ, 1997: 94. Ver también KINNER, 2005, VOL. 2: 166-167.

36 "Resolution des ZK der Kommunistischen Partei Deutschlands zur Lage (Beschlossen am 14. Mai 1938)“, Rundschau, pp. pp. 1109 y 1110, F/7/15131 Kommunistische Partei Deutschland (K.P.D.) 1934-1939), AN (Paris).

37 HÁJEK, 1984: 298-299. DEGRAS, 1965: 334-335. Para ambos autores, hasta los primeros meses de 1935 la mayor parte del Buró Político del KPD -Schubert, Schulte, Florin, Heckert y Dahlem- rechazaba el frente único, mientras Ulbrich y Pieck lo defendían. Franz Dahlem (miembro de la Comisión Política Central de las Brigadas Interncionales, junto a Luigi Longo y André Marty) cambiará de actitud en el VII Congreso del Comintern y criticará la línea "izquierdista" de Schubert y Schulte, y en la conferencia de Bruselas del KPD, octubre de 1935, introducirá la propuesta de infiltrar las organizaciones nazis de masas en su informe Die revolutionäre Organisation in Deutschland - Formen und Methoden der illegalen Massenarbeit, Nationalsozialismus, Holocaust, Widerstand und Exil 1933-1945. Online-Datenbank. De Gruyter. Oct 20, 2011. http://db.saur.de/DGO/basicFullCitationView.jsf?documentId=BHB-0578

38 Sozialistische Arbeiterpartei Deutschlands (también SAPD). 
Arnold Zweig y Lion Feuchtwanger ${ }^{39}$. Más tarde se producirá el acuerdo del KPD con los «Diez puntos» ${ }^{40}$ presentados por militantes del SPD a la ejecutiva del partido en Praga, en abril de 1937, y remitidos también al comité central del KPD en junio de 1937, en los que se enumeraban los objetivos para una Alemania liberada del nazismo. Dichos puntos incluían una completa restauración democrática con plenas libertades públicas y ciudadanas, la nacionalización de la banca, de la industria pesada y de la producción de energía y una reforma agraria basada en la expropiación de la gran propiedad terrateniente $^{41}$. En dicho acuerdo, firmado por Wilhelm Pieck, ya se adelantaba la táctica del «caballo de Troya» en el interior y se reconocía la importancia de las actividades de apoyo que se realizaban o podían realizarse en el exilio ${ }^{42}$.

Habría que agregar la reivindicación de las fórmulas colectivistas materializadas especialmente en Cataluña durante la guerra como indicios orientadores sobre el tipo de organización social que impulsaba el proyecto de frente popular para Alemania, una vez derrotado el fascismo. En un informe para el KPD sobre el Tercer Congreso de la UGT de Cataluña, celebrado en noviembre de 1937, en el apartado referido a las empresas colectivizadas, se afirmaba y saludaba como uno de los éxitos del congreso que se hubieran aplicado correctivos para adecuar esas empresas a la producción de guerra para mejorar su eficiencia en el sentido de avanzar hacia la planificación centralizada, a la diferenciación salarial según categorías y a la recuperación de la disciplina laboral, «... fuertemente afectada en Cataluña, como sucede en todo proceso revolucionario», pero que dichos correctivos «no debían significar en ningún caso el retorno a las condiciones económicas y sociales anteriores a julio de 1936». Para los comunistas alemanes la colectivización y planificación de la economía trascendían lo circunstancial y significaban las características fundamentales del modelo que debía prevalecer en la reorganización social de la postguerra ${ }^{43}$.

39 Llamado «Círculo Lutetia» porque se constituyó formalmente en ese hotel de París el 26/9/1935. Benz, 2004: 194-195. Ver también DEGRAS, 1965: 388-389.

40 Los impulsores de esta plataforma eran: Otto Brass, Hermann Brill, Oskar Debus (SPD) y Elli Schnmidt (alias Irene Gärtner) KPD-IC, BENZ, 2004: 195.

41 También podemos considerar como hitos la conferencia celebrada en Annemasse (ciudad francesa en la frontera con Suiza), el 21 de junio de 1937, en la que Sozialistische Arbeiterinternationale (SAI) y el COMINTERN habían acordado la ayuda a la Segunda República española como reacción ante el bombardeo de Guernica por la "Legión Cóndor" y de Almería por la marina nazi.

42 SAPMO-BArch, SgY 11/ V 237 1/12, "Die 10 Forderungen sozialdemokratischer Genossen aus dem Land"; "Sozialdemokraten und Kommunisten stehen und gehen zusammen"; "Die Antwort der Verfasser der Zehn Punkte". Los militantes socialistas «representantes de los diez puntos (Der Verfasser der Zehn Punkte)» además de instar al acuerdo criticaban la reticencia de la ejecutiva de Praga para concluirlo.

43 “Der III. Kongress der UGT von Katalonien”, F/7/15131, 8 b. b1., AN (Paris), s/f. 


\section{EL DEBATE SOBRE LA UNIDAD DE ACCIÓN Y EL FRENTE POPULAR EN ESPAÑA}

\section{El Comité de Unidad de Albacete}

Cabe destacar en especial la importancia que adquiriría en estos debates la constitución el 8 de diciembre de 1937 de un Comité de Unidad en Albacete y de un comité de unidad socialdemócrata y comunista de la XI Brigada, en febrero de 1938, con los objetivos de influir en la revitalización del comité del Frente Popular de París - paralizado por los desacuerdos entre responsables comunistas y socialdemócratas - y de impulsar un movimiento a favor de un Frente Popular para Alemania; con este fin, contaban con aprovechar, como factor decisivo, la popularidad de la que gozaban los miembros de las Brigadas Internacionales entre la oposición antinazi incluso en el interior de Alemania ${ }^{44}$. El Comité de Albacete era considerado por quienes habían participado en su constitución como la formalización de una acción conjunta entre SPD y KPD, que se había producido desde el primer momento de su intervención en la contienda española ${ }^{45}$. La democracia debía ser fundamento incondicional de las decisiones del Comité, el cual a su vez, como objetivación de la unidad socialdemócrata-comunista, renunciaba a la absorción o trasvase de militantes de una a otra organización. Un aspecto central de los fundamentos de constitución de este comité era que la intervención de socialistas y comunistas alemanes en España no era sólo en solidaridad con el pueblo español en su lucha contra el fascismo, sino que además era una forma concreta y práctica de combatir a la dictadura nazi, a la cual se la enfrentaba en esa contienda no sólo desde una perspectiva ideológica e internacionalista, sino de forma directa debido a la implicación material del régimen nazi a favor de Franco. Además, y ese era otro aspecto esencial en la constitución del comité de Albacete, admitía que la eficacia de ese enfrentamiento directo con el fascismo en suelo español era consecuencia de la unidad fundamental alcanzada entre comunistas y socialistas alemanes en la acción política, incluida la del campo de batalla, el cual, a su vez encontraba inspiración en el esfuerzo unitario de las fuerzas republicanas. Por lo tanto el Comité de Albacete pretendía con su propia existencia demostrar la posibilidad y la necesidad del frente único, como base y condición de un frente popular alemán, que debía ser operativo tanto en el interior como en el exilio. En consecuencia expresaban la

44 F/7/15131, 8 b. b1., AN (Paris), 21/01/1938, y «Al Secretariado del CC. del Partido Comunista de España resp. a la comisión para el trabajo entre los antifascistas extranjeros» SAPMO-BArch, SgY 11/V237/1/9. Ver también, NIEMEYER, 2001: 133-134. Para la crisis del Comité del Frente Popular alemán, ver LANGKAU-ALEX, 2004, VOL. 2: 431-458.

45 SAPMO-BArch, SgY 11/ V 237/1/13, P. 11. 
necesidad de una estrecha vinculación entre la dirección del SPD residente en Praga, los centros socialistas en el exilio y el Comité Central del KPD ${ }^{46}$.

Este comité se proclamaba «representante de todos los socialistas y comunistas combatientes en España», y como clara voluntad de unión establecía una representación paritaria - tres miembros por cada partido - en la dirección del mismo ${ }^{47}$. En una carta de la XI BI a la dirección del SPD (Praga), al CC del KPD y al Comité del Frente Popular Alemán de octubre de 1937 — esta última, dirigida a Heinrich Mann, quien lo presidía - los miembros del comité insistían en la necesidad de la unidad de ambos partidos y la consolidación del Frente popular. Igualmente, citaban la intervención de Louis de Bruckère dirigida a los brigadistas, quien —en su calidad de dirigente de la II ${ }^{\mathrm{a}}$ Internacional - exponía el ejemplo de la lucha del pueblo español y de las Brigadas Internacionales en el combate contra el fascismo como resultados positivos de la unidad antifascista, mencionando la ofensiva de Brunete y la conquista de Teruel. Además citaban la decisión de miembros del SPD en el interior de Alemania de pedir a la dirección de su partido en el exilio la erección del frente único en Alemania, la misma reivindicación que ellos hacían desde España ${ }^{48}$. El acuerdo entre brigadistas comunistas y socialdemócratas era pleno, tal como lo confirmaba S. Glogowski, militante socialista, quien reivindicaba al comité de unidad de Albacete, mientras reafirma la concepción dual y complementaria entre el frente único de trabajadores (asociación SPD-KPD) y el frente popular, este último integrando a aquel más los sectores sociales pertenecientes a la pequeña burguesía ${ }^{49}$. Concepción que se repite en otros documentos, en los que los miembros del comité de Albacete recurren a todas las instancias para dar a conocer su posición e intentar con ello influir en las direcciones de ambos partidos. Así, por ejemplo, al solicitar al director del Neue Weltbühne, Hermann Budzislawski, que publicara en este periódico del exilio de Praga y de orientación socialdemócrata los fundamentos del comité; o también la comunicación dirigida al Neuer Vorwärts, y Deutsche Freiheit, en enero de $1938^{50}$. Sin embargo, en la carta dirigida al

46 "Richtlinien für die Arbeit des Einheitskomitees deutscher Sozialdemokraten und Kommunisten in Spanien / Albacete“, F/7/15131, 8 b. b1., AN (Paris), 8/12/1937. Firman el documento: Ernst Braun, Kurt Garbarini y Hans Martens, por el SPD; Ernst Blank, Walter Knobloch y Willi Engler, por el KPD.

47 "Richtlinien für die Arbeit des Einheitskomitees deutscher Sozialdemokraten und Kommunisten in Spanien“, SAPMO-BArch, SgY 11/ V 237/ 1/13, p. 8.

48 "An den Vorstand der Sozialdemokratischen Partei Deutschlands Prag. An das Zentralkomitee der Kommunistischen Partei Deutschlands. An den Volksfrontausschuss, z.N. Von Heinrich Mann Paris“, SAPMO-BArch, SgY 11/V 237/ 1 /13, octubre 1937, p. 3.

49 S. Glogowski, "An die Redaktion von Volkszeitung“, SAPMO-BArch, SgY 11/ V 237/ $1 / 13,10 / 11 / 1937$, p. 5.

50 SAPMO-BArch, SgY 11/ V 237/ 1/13, p. 6 (s/f) y 27, 5/1/1938. 
Deutsche Volkszeitung (periódico perteneciente al KPD en el exilio) y a $L a$ Libertad (5/1/1938), junto a la comunicación de la constitución del Comité de Albacete, se les solicitaba que no publicaran la información hasta que los destinatarios principales - respectivamente, las direcciones del SPD y el KPD, así como el Comité para el Deutsche Volksfront - la recibieran. Que el acuerdo fuera difundido públicamente en los medios socialdemócratas, al tiempo que se solicitaba a los medios afines al partido comunista que se abstuvieran de publicarlo hasta que acusaran recibo las direcciones respectivas de ambos partidos, sugiere que los brigadistas de Albacete consideraban a la dirección del SPD más reticente a la constitución del Frente Único que la del $\mathrm{KPD}$, y, por lo tanto, habían optado por ejercer una presión selectiva, mayor sobre la vertiente socialdemócrata de las direcciones de ambos partidos, para superar las dificultades para llegar a un acuerdo entre las direcciones del SPD (Praga) y del KPD (París) que generalizaría el Frente Único, ya materializado en Albacete ${ }^{51}$. Esa presión selectiva se evidencia porque la comunicación pública del acuerdo iba siempre firmada por un miembro socialista del comité de unidad de Albacete, y además se publicaban cartas de militantes socialistas que se expresaban en el mismo sentido. Con ello se buscaba destacar la implicación y la decidida resolución de los brigadistas socialistas en la consecución de los acuerdos de Albacete, mensaje que se reforzaba manifestando la preocupación por las «incomprensibles dificultades de carácter secundario que parecían impedir la concreción del Deutsche Volksfront ${ }^{52}$. También revela que quienes estaban intentando impulsar ese acuerdo eran quienes soportaban el esfuerzo mayor en la lucha antifascista en ese momento. Era la razón por la que se consideran legitimados para forzar una decisión desde la base recuperando con ello, aunque fuera por un corto período, la relación entre contexto de actuación - milieu - y línea política que había caracterizado al KPD durante Weimar y que estaba en la base de la incompleta o resistida estalinización que se había producido según los autores mencionados.

A pesar de estos avances, la unidad efectiva no se hallaba al alcance de la mano. La dirección del KPD criticaba la representación paritaria de comunistas y socialdemócratas en el Comité de Albacete, así como su pretensión de representar a la totalidad de los miembros de ambos partidos en España. Esa representación debía ser fruto de la constitución de comités similares en Barcelona y Madrid, además del de Albacete. Karl Mewis ${ }^{53}$ y Franz Dahlem no

51 Kinner, 2005, vol. 2: 234. Para este autor esta presión está orientada por la propia dirección del KPD, sin embargo, la documentación examinada parece mostrar que era una iniciativa del Comité de Albacete.

52 SAPMO-BArch, SgY 11/ V 237/ 1 /13, pp. 29-30 y 33-36, 5/1/1938.

53 Sustituyó en diciembre de 1937 a Franz Dahlem como miembro de la Comisión Política Central de las Brigadas Internacionales; fue representante del KPD ante el C.C. del PSUC, 
estaban dispuestos a conceder la representación paritaria a los socialdemócratas (tal como se ha visto más arriba, el número de brigadistas socialdemócratas era muy inferior al de comunistas). Por esa razón Karl Mewis reprochaba a Ewald Blau ${ }^{54}$, miembro del KPD en el Comité de Albacete, por haber acordado con Ernst Braun, quien era miembro del SPD pero no tenía ninguna vinculación con el PSOE, la paridad para la constitución de dicho comité. Además le recriminaba que hubiera ignorado a otro grupo de socialistas alemanes, liderado por Rolf Reventlow, reconocidos por el partido socialista español ${ }^{55}$.

Pero los máximos responsables del KPD en España también debían afrontar una presión que procedía de los miembros del partido que estaban, junto a los socialdemócratas, directamente en la línea del frente objetivando esa unidad antifascista ${ }^{56}$. Fruto de esa autonomía respecto a la dirección demostrada por los brigadistas comunistas sería la participación de Ernst Braun en la conferencia de Valencia como uno de los ponentes, a pesar de haber sido cuestionada su presencia en el Comité de Albacete por Karl Mewis. Ewald Blau en su respuesta a Karl Mewis, en la que defendía los acuerdos alcanzados con los socialdemócratas en Albacete, presentaba a Ernst Braun como un defensor incondicional del Frente Único y el Frente Popular dispuesto a romper con la dirección del SPD si obstaculizaba esa línea, citando sus propias declaraciones ${ }^{57}$.

Nationalsozialismus, Holocaust, Widerstand und Exil 1933-1945. Online-Datenbank. De Gruyter. Dec 2, 2011. http://db.saur.de/DGO/basicFullCitationView.jsf?documentId=BHB-2421.

54 Ewald Blau (su nombre de guerra era Ernst Blank) se desempeñaba como comisario político de la XI Brigada Internacional, Nationalsozialismus, Holocaust, Widerstand und Exil 1933-1945. Online-Datenbank. De Gruyter. May 23, 2011, http://db.saur.de/DGO/ basicFullCitationView.jsf? documentId=BHB-0344 Dokument-ID: BHB-0344.

55 Ídem, P. 15 “An Ernst Blank - Albacete, Barcelona, 24.12.37”. En realidad Ernst Braun había revistado como voluntario en el Batallón Thälmann de la XI Brigada, ver Nationalsozialismus, Holocaust, Widerstand und Exil 1933-1945. Online-Datenbank. De Gruyter. May 23, 2011. http://db.saur.de/DGO/basicFullCitationView.jsf?documentId=BHB0424 Dokument-ID: BHB-0424

56 NIEMEYER, 2001: 164-166.

57 SAPMO-BArch, SgY 11/ V 237/1/13, P. 17, 27/12/1937, 18. Ernst Blank citaba esta declaración del miembro del SPD Ernst Braun: "si los parisinos (Breitscheid y Max Braun) corren el riesgo de disover el Frente Popular parisino, implicaría para mí acabar con el SPD" ["das wenn die Pariser (Breitscheid und Max Braun) es auf die Sprengung der Pariser Volksfront ankommen lassen, so mache ich Schluss mit der SPD"] y más adelante le comunicaba a Mewis que: "Lo decisivo es que tanto Braun como los otros camaradas se han orientado firmemente hacia el trabajo en común, y desean hacer del frente unido un factor contra las tendencias en París opuestas a la unidad" ["Das Entscheidende ist, das sowohl Braun, sowie die andern Kameradeneine feste Orienterung auf die gemeinsame Arbeit haben und das Einheitsfront hier zu einem Faktor gegen die einheitsfeindlichen Tendenzen in Paris, etc. machen wollen"] . 


\section{La Conferencia de Valencia}

La conferencia para la unidad de los antifascistas alemanes celebrada en Valencia el 13 de marzo de 1938, con la participación de 13 delegados comunistas y 9 socialistas, tenía como objetivo debatir la constitución del Frente Popular y sus posibilidades de desarrollo en la lucha contra la dictadura nazi tanto en el interior de Alemania como en los medios del exilio antifascista, cuya sede principal se hallaba en París; y todo ello a partir de la experiencia del Frente Popular español recogida por los exiliados alemanes que estaban colaborando con la Segunda República, y especialmente los miembros alemanes de las Brigadas Internacionales ${ }^{58}$. Fue convocada por iniciativa del comité unitario de la XI Brigada, y de los tres puntos que constituían el orden del día, el segundo rezaba: «La significación de la derrota de Franco, Hitler y Mussolini en España para la lucha de las masas de Alemania para la caída de la dictadura fascista ${ }^{59}$.

Los ejes del debate, respondiendo al orden del día de la misma, se refirieron a las contribuciones que la experiencia española podía aportar para la constitución de un frente popular alemán, a las características que dicho frente debía adquirir y las tareas que debía emprender una vez derrocada la dictadura nazi y también a la importancia de la recuperación del concepto de Frente Único como eje alrededor del cual debía girar la construcción de Deutsche Volksfront ${ }^{60}$. En general hubo acuerdo en cada uno de ellos entre los delegados comunistas y socialistas, y especialmente en la necesidad de recuperar la fórmula del Frente Único, que sellaría la imprescindible unidad entre KPD y SPD sin condiciones previas. Ello revela que para el comunismo alemán, o al menos para quienes estaban protagonizando el combate contra el fascismo en España, había llegado la hora de enterrar todos los resquemores y desconfianzas, todos los desgarros entre KPD y SPD que databan como mínimo desde 1928, y que habían conducido al desastre de 1933. Por esa razón se reivindicaba la Conferencia de Bruselas de octubre de 1935, en la que el KPD había confirmado la línea aprobada por el VII Congreso del Comintern y se asumían

58 Estaba prevista la asistencia de 32 delegados, pero el recrudecimiento de la lucha en Belchite había retenido a varios de los delegados en el frente, SAPMO-BArch, SgY 11/ V 237 1/12: "An der Verstand der SPD und das Z.K. der KPD", 78.

59 SAPMO-BArch, SgY 11/ V 237 1/9, "Al Secretariado del CC. del Partido Comunista de España resp. a la comisión para el trabajo entre los antifascistas extranjeros", 2. Los otros dos puntos eran 1) "La unidad es la garantía de la victoria sobre los invasores fascistas" y debían intervenir un representante del comité de enlace del PCE y otro del PSOE y 2) "Elección del Comité de Unidad de los antifascistas alemanes en España, 5-7.

60 SAPMO-BArch, SgY 11/ V 237 1/12: "Referat von Fritz Arndt", 1-4.SAPMO-BArch, SgY 11/ V 237 1/12: "Diskussionsredner: Friedrichs, Barcelona", 15-18. SAPMO-BArch, SgY 11/ V 237 1/12: "Diskussionsredner: Kettner", 29-30. 
los objetivos planteados poco tiempo antes por Wilhelm Pieck, que coincidían con los establecidos en los «Diez Puntos» de abril de 193761. Respecto a estos últimos, Mewis cerraba los debates planteando que la reconstrucción de Alemania después del final de la dictadura pasaría por la constitución de una nueva republica democrática que «tendría poco en común» con la República de Weimar, ya que constituiría una etapa hacia la construcción del socialismo ${ }^{62}$.

Los socialdemócratas presentes, a su vez, reforzaban estas propuestas considerando que era imprescindible la inmediata constitución del Frente Popular alemán, y lanzaban la idea de un «contra-eje», que implicaba un frente internacional que agruparía a socialistas y comunistas alemanes, austríacos e italianos. ${ }^{63}$ Pero al mismo tiempo afirmaban que la construcción del mismo debía adecuarse a las condiciones existentes y a las tradiciones culturales, sociales y políticas de cada país. Ponían como ejemplo de las diferencias que afrontaba la constitución y objetivos del mismo los casos de Austria, donde un objetivo primordial era recuperar la independencia, liberándose del yugo nazi, y de Francia, donde esta situación no se daba ${ }^{64}$. El caso austríaco estuvo presente en casi todos los parlamentos durante esta conferencia, no sólo porque tenía obvias vinculaciones con Alemania y demostraba la agresividad de la política exterior de Hitler (no olvidar que la conferencia se celebraba al día siguiente de consumarse la ocupación de Austria por los nazis), sino porque servía también como contraste con el caso español, ya que a pesar de la unidad de socialistas y comunistas no se había conseguido sumar a la alianza a las clases medias, lo que sí había sucedido en España. En ese sentido cobra valor la pregunta retórica de Karl Mewis:

¿Existe alguna duda sobre quien conduce a las masas en España, no vemos cotidianamente las medidas adoptadas por los comités conjuntos del partido comunista y socialista y la actividad de los órganos del Frente Popular, que hacen posible su éxito? ${ }^{65}$

El éxito era, por lo tanto, atribuido no sólo a la unidad comunista y socialista, sino también a la alianza con los sectores sociales ajenos a la clase obrera. Los diferentes oradores también coincidían en que, siguiendo el ejemplo espa-

61 SAPMO-BArch, SgY 11/ V 237 1/12: "Vorschläge zur Schaffung einer deutschen Volksfront. Entwurft von Wilhelm Pieck, Vorsitzender des ZK der KPD, 41-45.

62 SAPMO-BArch, SgY 11/ V 237 1/12: "Aus dem Schlusswort von Fritz", 45-47.

63 SAPMO-BArch, SgY 11/ V 237 1/12: "Diskussionsredner: Ernst Braun", 38-39.

64 Situación que se modificaría pocos años después, cuando a partir de 1940 la lucha por la independencia nacional se transformaría también en un objetivo de la lucha unitaria antifascista en Francia.

65 SAPMO-BArch, SgY 11/ V 237 1/12, 43: "Schlusswort von Fritz Arndt". 
ñol, en Alemania también debían hacerse los esfuerzos necesarios para incorporar a los partidos burgueses a la lucha contra la dictadura, aunque teniendo en cuenta las mayores dificultades y las diferentes condiciones de la lucha antifascista en ambos países, que en España se realizaba mediante la confrontación armada y con el soporte de una estructura de estado, mientras que en Alemania debía realizarse en condiciones de rigurosa clandestinidad, lo que dificultaba la vinculación estable con las clases medias.

También deben consignarse diferencias en las opiniones sostenidas por los participantes en la conferencia. Unas hacían referencia a las condiciones distintas impuestas al frente popular español y al hipotético en Alemania, así como a la importancia que el KPD otorgaba a la incorporación de las clases medias en dicho frente. Otro de los puntos de fricción fue el párrafo de la carta dirigida al comité central del KPD y a la ejecutiva del SPD, donde se consideraba la «...necesidad de la eliminación del trotskismo», ya que una parte de los delegados socialdemócratas había manifestado su desacuerdo con esa exigencia, aunque otros delegados socialdemócratas estaban dispuestos a aceptarla ${ }^{66}$. Este debate reflejaba, por una parte, la incapacidad de los miembros del KPD para distanciarse de las consignas que procedían de Moscú y que apoyaba el Comintern, contribuyendo a la criminalización de quienes eran víctimas de las purgas, en el momento en que culminaba la «tercera ola» de los juicios de Moscú, ya que esa declaración no había sido introducida en los documentos que certificaban la constitución del Comité de Albacete ${ }^{67}$. Posiblemente esa ausencia de sectarismo en la constitución de este comité había facilitado el encuentro entre socialdemócratas y comunistas. Pero tampoco el rechazo a la criminalización de los perseguidos por Stalin en el encuentro de Valencia había alcanzado suficiente intensidad como para bloquear la marcha del mismo, como lo refleja la falta de acuerdo de los socialdemócratas participantes sobre esa cuestión. Posiblemente había actuado como mecanismo compensatorio el reconocimiento en el curso de dicha conferencia de que la unidad antifascista podía lograrse incluso entre organizaciones que podían mantener «...diferencias tácticas e incluso en las cuestiones fundamentales» al aceptar como natural y lógico que los comunistas se encontraran compartiendo ese frente común con los anarquistas o los republicanos, tal como lo demostraba el caso de la República española. Una cuestión sobre la que insistiría también Franz Dahlem en un artículo titulado "Qué deben aprender los alemanes de los españoles», señalando que la presencia mayoritaria de los anarquistas en el movimiento

66 SAPMO-BArch, SgY 11/ V 237 1/12: "Bericht über die Einheitskonferenz der deutschen Antifaschistenvom 13. März 1938 in Valencia", 162-163; "Die Konferenz der deutschen Antifaschisten in Spanien", 160.

67 SAPMO-BArch, SgY 11/ V 237 1/13: «Antwort an eine Reihe sozialdemokratischer Funktionäre die Verfasser des «Mahnruf zur Einheit», 85. 
obrero, si bien era una dificultad añadida al desarrollo de la unidad frentepopulista, no la consideraba un obstáculo para la misma. Los distinguía del POUM, al que adjudicaba la habitual filiación «trotskista», y afirmaba que la unidad entre UGT y CNT había permitido superar las fisuras y amenazas debidas a la incapacidad de Largo Caballero como presidente de gobierno ${ }^{68}$. Es razonable pensar que las dificultades para materializar la unidad de socialdemócratas y comunistas en Alemania actuaban como acicate para concretarla en el exilio. Así permite suponerlo un llamamiento que efectúan los representantes de las juventudes en el exilio, tanto comunistas como socialdemócratas, dirigido a las organizaciones juveniles comunistas, socialdemócratas, católicas, evangélicas e incluso a los jóvenes en las organizaciones nazis en el interior de Alemania, para actuar unitariamente contra el nazismo ${ }^{69}$. Por ello es de suponer que en España el propio contexto, en razón del dramatismo con el que se realizaba una activísima praxis de lucha contra el fascismo, actuara aún como mayor acicate para la unidad. Para destacar todo ello, la Conferencia de Valencia registraba la constitución en Albacete de un Comité de Unidad entre socialdemócratas y comunistas alemanes, así como otro similar en Barcelona ${ }^{70}$.

A pesar de los puntos de fricción mencionados, que reflejaban la persistencia de dificultades para superar la mutua desconfianza y los enfrentamientos entre comunistas y socialistas, la culminación de la conferencia delataba su éxito, al obtenerse acuerdos que resultaban de gran utilidad para el trabajo del KPD, resumidos en la conclusión predominante: «España enseña que la unidad de socialdemócratas y comunistas es la clave para la victoria, el Frente Popular es el martillo con el cual destruir el fascismo» ${ }^{71}$.

\section{CONCLUSIONES}

El impacto que produjo la guerra civil en los comunistas alemanes no fue acusado exclusivamente por ellos. En realidad afectó en mayor o menor grado

68 SAPMO-BArch, SgY 11/ V 237 1/12, Franz Dahlem, «Was wir Deutsche von den Spaniern lernen sollen“, 129-130. La postura de Dahlem es idéntica a la sostenida por el PCE cuando tendió su mano a la CNT por boca de José Díaz en su informe de noviembre de 1937.

69 SAPMO-BArch, SgY 11/ V 237 1/12: "Für die Lebensrechte der jungen Generation", 124125. Firman el documento, Willi Brandt, por la juventud socialista, Karl Kunert por la juventud comunista, Edwin Sander, por la juventud obrera socialista, Otto Friedlander, por los Estudiantes socialistas en Alemania, quienes conforman los grupos en el exilio de la Juventud Alemana Libre.

70 SAPMO-BArch, SgY 11/ V 237 1/12: "Die Konferenz der deutschen Antifaschisten in Spanien“, 158.

71 SAPMO-BArch, SgY 11/ V 237 1/12: "Die Konferenz der deutschen Antifaschisten in Spanien”, 156; "Bericht über die Einheitskonferenz der deutschen Antifaschisten vom 13. März 1938 in Valencia“, 162-163. 
a todo el ámbito comunista internacional, hasta el punto que un miembro de la importancia de Palmiro Togliatti, enviado especial del Comintern, se comportó como tal de un modo no convencional, distinto a las actuaciones de los agentes de la internacional en otras coyunturas; cambiando su papel de transmisor de instrucciones desde la ECCI hacia el PCE, en el de mediador de las relaciones entre los comunistas españoles, la IC y Moscú; y que halló en la praxis española los fundamentos para elaborar el concepto de «democracia de nuevo tipo» que estaba sólo esbozado en las propuestas originales del frente popular de $1935^{72}$. Pero es indudable que en los militantes del KPD tuvo un efecto específico porque era el partido que con mayor retraso había reconocido la necesidad de la unidad con otras fuerzas de izquierdas. Habían comprobado y habían demostrado al resto del movimiento antifascista su capacidad para enfrentar al fascismo, y habían experimentado como consecuencia de ello una recuperación de su autoestima al redimir en parte la responsabilidad que les cabía por no haber sabido impedir junto a la socialdemocracia la llegada del nacionalsocialismo al poder en 1933. Pero al mismo tiempo la actividad de los comunistas alemanes en España no se había limitado a las tareas militares, sino que habían continuado recreando un trabajo político interno pero también en relación con la población autóctona. Este último factor, producto de su interacción con el tejido social local, que les permitía comportarse no sólo como una fuerza político militar sino también como una organización social, debe de haber contribuido a la reconstrucción de ese «milieu» del que habla Mallmann. También lo permitió la entente con los brigadistas socialdemócratas, tal como hemos visto a lo largo de este trabajo, tanto por las características de estos últimos, críticos con la renuencia de la dirección del SPD de Praga a apostar por el Frente Único, como porque el «nicho ecosocial» en suelo peninsular era construido simultáneamente por ambas tendencias, sin que ninguna precediera a la otra, tal como había sucedido en la evolución del movimiento obrero en Alemania.

Los acontecimientos examinados en este texto contribuyen a mostrarnos que la guerra civil española se convertiría en un escenario clave, desde la perspectiva del KPD, para lograr la unidad en la lucha contra Hitler en el exilio y en el interior de Alemania. La experiencia de unidad en la lucha contra los militares sublevados y sus aliados nazi-fascistas se convertía en la recomendación principal y la lección más importante a extraer para aplicarla a la lucha clandestina en Alemania, así como a la actividad de las organizaciones en el exilio, y se la comparaba con la falta de unión que había permitido la

72 LAPORTE, 2008: 176-179. Ver también el testimonio del propio TOGLIATTI, 1980: 143-147, en el que también defiende la necesidad de aproximarse a la CNT «sin romper o enfriar las relaciones con los socialistas y con los demás partidos del FP», p. 145. 
llegada al poder de los nazis ${ }^{73}$. Su lucha como brigadistas les permitió realizar una experiencia directa de lucha contra el fascismo así como demostrar la factibilidad del frente único con sus compañeros socialdemócratas, ampliando incluso la alianza a otros militantes demócratas. La derrota de los sublevados en España se había transformado en un factor esencial en el derrocamiento del nazismo. De este modo, la lucha internacionalista de los comunistas alemanes era incorporada no sólo simbólicamente sino también fácticamente a la lucha contra el fascismo en el interior de Alemania, tal como enunciaba el orden del día de la Conferencia de Valencia. Para el logro de esa unidad actuaba también como acicate el sentimiento de una obligación ante el propio pueblo que estaban tratando de ayudar, tal como refleja este párrafo:

Es para nosotros humillante que no podamos todavía dar cuenta a nuestros camaradas españoles del logro de la unidad total entre el SPD y el KPD y agrupar a todas las fuerzas antifascistas en la lucha contra la política belicista de $\mathrm{Hitler}^{74}$.

Ello sugiere también que el peso adquirido por los militantes del KPD en el frente de batalla como miembros de las Brigadas Internacionales les había permitido recuperar un mayor nivel de autonomía en el debate interno y en la relación con otras organizaciones. Otra muestra de ello fue la actitud de varias decenas de militantes comunistas alemanes, predominando entre ellos los excombatientes de las Brigadas Internacionales, que en agosto de 1939 firmaron junto a Willi Münzenberg, en ese momento expulsado del KPD y el Comintern, un documento a favor de la unidad socialista en Alemania bajo el significativo título «Quien conoce la verdad y no la expresa, es un cobarde» ${ }^{75}$. Para quienes habían firmado el documento, éste tenía dos destinatarios. Por una parte el SPD, ya que con ese texto defendían una acción unitaria en la que se manifestaba la predisposición a efectuar concesiones a sus interlocutores socialistas. Con ello reconocían que la solidez de los frentes populares exigía una amplitud tal que debían incluir a fuerzas que en otro tiempo hubiesen sido consideradas ajenas al movimiento comunista, como era el caso de las corrientes anarquistas; o sea, sometiendo la política de alianzas a las condiciones específicas de cada país. Pero también se dirigían al comunismo alemán, ya que las militantes del KPD respaldando un documento junto a Münzen-

73 SAPMO-BArch, SgY 11/ V 237 1/12, 80-82: “An den Parteivorstand der Sozialdemokratischen Partei Deutschlands! An das Zentralkomitee der Kommunistischen Partei Deutschlands!“

74 NIEMEYER, 2001: 135.

75 "An die Mitglieder und Freunde der Gruppe 'Freunde der sozialistischen Einheit Deutschlands"“, Paris, 4/8/1939, AN F7/15129 “Amis de l'Unité Socialiste en Allemagne“, 3, 3a1. En ese documento además se defendía la trayectoria de Münzenberg a favor del frente único y del frente popular. 
berg, transformado en ese momento en un proscripto por el aparato partidario, demostraban una autonomía política que, al menos en parte, debe ser atribuida a la recuperación de su legitimidad política en tierras peninsulares. Una experiencia de la que derivaba también otra característica de los miembros del KPD en España, su apuesta decidida por la definición del carácter democrático radical, político y social que debería adquirir Alemania, una vez vencida la dictadura fascista.

\section{BibLIOGRAFÍA}

Agosti, Aldo, Togliatti. Un uomo di frontiera, Torino, UTET, 2003

Andreassi, Alejandro, «Willi Münzenberg, el gran comunicador rojo o 'La propaganda como arma'. La lucha por la opinión pública del Frente Único al Frente Popular» en Alejandro Andreassi y José Martín Ramos (coords.), De un octubre a otro : revolución y fascismo en el periodo de entreguerras, 1917-1934, Mataró, Ediciones de Intervención Cultural/El Viejo Topo, 2010; 35-71.

Benz, Wolfgang, Lexikon des deutschen Widerstandes, Frankfurt am Main, Fischer, 2004.

Broué, Pierre, Histoire de l'Internationale communiste. 1919-1943, Paris, Fayard, 1997.

Castells, Andreu, Las Brigadas Internacionales de la guerra de España, Barcelona, Editorial Ariel, 1974.

Dahlem, Franz, Am Vorabend des zweiten Weltkrieges:1938 bis August 1939: Erinnerungen Franz Dahlem., Berlin, Dietz Verlag, 1977.

Degras, Jane, The Communist International, 1919-1943 : documents, London, Frank Cass, 1965.

Gallego Margaleff, Ferran, Barcelona, mayo de 1937: la crisis del antifascismo en Cataluña, Barcelona, Debate, 2007.

Gross, Babette, Willi Münzenberg: Una Biografía Política, Vitoria-Gasteiz, Ikusager, 2007.

Hájek, Miloš, Historia De La Tercera Internacional: La Política De Frente Único: 1921-1935, Barcelona, Crítica, 1984.

Harsch, Donna, German social democracy and the rise of Nazism, Chapel Hill London, The Univesity of North California Press, 1993.

Kinner, Klaus, Der deutsche Kommunismus. Selbstverständnis und Realität. Gegen Faschismus und Krieg : (1933-1939), Berlin, Dietz, 2005.

Langkau-Alex, Ursula, Deutsche Volksfront 1932-1939: zwischen Berlin, Paris, Prag und Moskau, Berlin, Akademie Verlag GmbH, 2004.

Laporte, Norman, Bolshevism, Stalinism and the Comintern: perspectives on Stalinization, 1917-53, Basingstoke, Palgrave Macmillan, 2008. 
Mallmann, Klaus-Michael, Kommunisten in der Weimarer Republik: Sozialgeschichte einer revolutionären Bewegung, Darmstadt, Wissenschaftliche Buchgesellschaft, 1996.

Mallmann, Klaus-Michael, «Gehorsame Parteisoldaten oder eigensinnige Akteure? Die Weimarer Kommunisten in der Kontroverse - Eine Erwiderung», Vierteljahrshefte für Zeitgeschichte 3 (Berlín, 1999): 401-415.

Martín Ramos, José Luis (ed.), Els fets de maig, Ediciones de Intervención Cultural/El Viejo Topo, 2010.

Merson, Allan, Communist resistance in Nazi Germany, London, Lawrence and Wishart, 1985.

Nelles, Dieter, Linse, Ulrich, Piotrowski, Harald, García, Carlos, Antifascistas alemanes en Barcelona (1933-1939). El Grupo DAS: sus actividades contra la red nazi y en el frente de Aragón, Barcelona, Sintra, 2010.

Niemeyer, Ralph, Die KPD und der Spanische Bürgerkrieg 1936-1939, Hamburg, Diplomica GmbH, 2001.

Peukert, Detlev, Die KPD im Widerstand: Verfolgung und Untergrundarbeit an Rhein und Ruhr 1933 bis 1945, Wuppertal, Peter Hammer Verlag, 1980.

Requena Gallego, Manuel, «Albacete, base de las Brigadas Internacionales, 19361938» en Manuel Requena Gallego (coord.), La Guerra Civil Española y las Brigadas Internacionales, Cuenca, Ediciones de la Universidad de Castilla - La Mancha, 1998; 147-179.

Skoutelsky, Rémi, Novedad en el frente. Las Brigadas Internacionales en la guerra civil, Madrid, Ediciones Temas de Hoy, 2006.

Togliatti, Palmiro, Escritos Sobre La Guerra De España, Barcelona, Crítica, 1980.

Viñas Ángel, El escudo de la República : el oro de España, la apuesta soviética y los hechos de mayo de 1937, Barcelona, Editorial Crítica, 2007.

Weber, Hermann, Die Wandlung des deutschen Kommunismus die Stalinisierung der KPD in der Weimarer Republik. Frankfurt am Main, Europäische Verlagsanstalt, 1969.

Weitz, Eric D, Creating German Communism, 1890-1990: From Popular Protests to Socialist State, Princeton, Princeton University Press, 1997.

Recibido: 16/01/2012

Aprobado: 26/04/2013 